\title{
Impact of Pregnant Advanced Cardiopulmonary Resuscitation Training Program on Maternity Nurses' knowledge, Attitude and Practice in Beni-Suef City
}

\author{
${ }^{1}$ Safaa Soliman Ahmed, ${ }^{1}$ Nahed Mousa Saber, ${ }^{*}$ Hanan Elzeblawy Hassan \\ ${ }^{2}$ Eman Hessien Heggy \\ ${ }^{1}$ Maternal and Newborn Health Nursing, Faculty of Nursing, Beni-Suef University, Egypt \\ ${ }^{2}$ Medical Surgical Nursing, Faculty of Nursing, Mansoura University, Egypt \\ *Maternal and Newborn Health Nursing Department, Faculty of Nursing, Beni-Suef University, Egypt \\ nona_nano_1712@yahoo.com
}

\begin{abstract}
Background: Maternal Mortality Rate (MMR) is the major universal concern. Emergency care should be done by nurses with ahigh quality of chest compressions and rapidly advanced airway management in cardiopulmonary resuscitation (CPR) for pregnantwomen. The ability to respond quickly and effectively to cardiac arrest situation rests on health care team and maternity nurses being competent in the emergency lifesaving procedure of cardiopulmonary resuscitation.
\end{abstract}

Aim: Assess the effect of pregnant advanced cardiopulmonary resuscitation learning package on maternity nurses' knowledge, attitude, and practice.

Methods: Aquasi-experimental research design was used in this study composed of 85 nurses from all maternity departments in the Beni-Suef University Hospital and General Hospital. Data were collected using astructured interview to assess nurses' knowledge, attitude and practice pre/post learning package of cardiopulmonary resuscitation for pregnantwomen.

Results: The study findings demonstrate statistically significant improvement in nurses' knowledge, attitude and practice scores. However, the post-knowledge score reported high score (84.7\%), the attitude modified about (87.1\%) with high level and almost (92.9\%) were met the CPR practice technique.

Conclusion: Overall, the majority of nurses' knowledge, attitude and practices toward cardiopulmonary resuscitation in Beni-Suef city were neither sufficient nor favorable. All of the studied participants didn't practice CPR. After implementation the program, overall, the majority of participants had apositive attitude about CPR.

Recommendation: The study is recommended that a training program should be conducted and a simple manual of guidelines of advanced cardiopulmonary resuscitation for pregnant women should be made available in all maternity units to be provided to newly employed nurses.

Keywords: Enhancing, knowledge, attitude, practice, Advanced Cardiopulmonary Resuscitation INTRODUCTION

Maternal Mortality Rate (MMR) is the major universal concern that affects family and thus society, the population division, world population prospects 2012, WHO, UNICEF, UNFPA and the world bank estimates 2013, reported the annual number of births in Egypt is 1,640,339 and theannual numberof maternaldeathsis 860 [1,2]. However immediately advanced Cardiopulmonary Resuscitation (CPR) is very important to apply to pregnant women. Despite the overall decline in the MMR, the distribution of causes hasn't changed dramatically, unfortunately, 
Impact of Pregnant Advanced Cardiopulmonary Resuscitation Training Program on Maternity Nurses' knowledge, Attitude and Practice in Beni-Suef City

Hemorrhage, both antepartum hemorrhage (APH) and postpartum hemorrhage (PPH) continuous to be the major cause of maternal deaths in Egypt as in many other countries [3].

Emergency care should be done by nurses and physician with ahigh quality of chest compressions and rapidly advanced airway management in cardiopulmonaryresuscitation (CPR) for pregnant women [4]. According to European Resuscitation Council (ERC), 2010, guidelines recommend implementing manual displacement of the uterus with left lateral tilt (LLT) to aortocaval decompression during CPR in late pregnancy moreover, the optimal degree between $15^{\circ}$ and $30^{\circ}$ [5]. In addition, the maternal cardiac arrest commonly occurs at delivery room or emergency room and several methods are available to achieve the LLT position, whereas the operating table is used in the operating room [6-8].

Aresearch studied the difference in mortality between pregnant and non-pregnant women after cardiopulmonary resuscitation, and found among 5,923 women received inpatient CPRannually the mortality rates after CPRwere lower among pregnant women than non-pregnant women [9]. Unfortunately, many causes of cardiac arrest in pregnancy are amniotic fluid embolism, hemorrhagic shock, eclampsia, pulmonary thromboembolic events, sepsis, anaphylaxis, trauma, congenital, and acquired cardiac diseases [10,11]. Furthermore, the cesarean section is increasing as an immediate solution to survive mother/fetus or both, as well as successful and early CPRif selected can be achieving optimal outcome [12]. The correct and fast resuscitator leads to optimal survival rates for both mother and fetus, however, early restoration of the mother circulation can increase the survival rate of the fetus [13]. Moreover; little is known about outcomes of cardiopulmonary resuscitation in pregnancy, although, further studies are needed [14].

\section{SigNIFICANT OF THE STUDY}

Cardiopulmonary resuscitation is an important medical and nursing procedure which is performed in an effort to manually preserve intact brain function until further measures are taken to restore normal spontaneous blood circulation and breathing in a person in cardiac arrest. It is a combination of rescue breathing and chest compression, which is delivered to the victims who are thought to be in cardiac arrest[15]. As nurses comprise the greatest group of health-care providers and are the ones responsible for the quality of care provided to the patients, their perspectives on the effectiveness of their care are very important. However, nurses possess a wide variety of holistic skills and there is evidence of nursing interventions that are proving to be valuable in saving cardiac arrest [16-18].

Being important members of the health-care team; maternity nurse is deemed to passes the basic skills and expertise which are needed to perform CPR. The management of cardiac arrest in the pregnancy is considering an important task in the emergency department and delivery room, however, all medical staff especially nurses should be applying CPR for pregnant women skillfully and following general advanced cardiac life support guideline [19]. The pregnant women havea various anatomical and physiological changes and the cardiopulmonary resuscitation is consideringa challenging operation [20]. The ability to respond quickly and effectively to cardiac arrest situation rests on health care team and maternity nurses being competent in the emergency life saving procedure of cardiopulmonary resuscitation [21].

\section{OPERATIONAL DEFINITION}

Cardiopulmonary Resuscitation: An emergency procedure in which the heartand lungs are made to work by compressing the chest over lying the heart and forcing air into the lungs. CPR is used to maintain circulation when the heart has stopped pumping on its own [22].

Knowledge: Respondent who answers $\geq 60 \%$ total knowledge question have sufficient knowledge and $<40 \%$ has insufficient knowledge about CPR [21]. 
Impact of Pregnant Advanced Cardiopulmonary Resuscitation Training Program on Maternity Nurses' knowledge, Attitude and Practice in Beni-Suef City

Attitude: Manner of acting or social or clinical psychology a relatively stable and enduring predisposition to behave or react in a certain way toward people, objects, institutions, or issues [22]. In our study, it refers to correct response of studied participants regarding CPRfor selected emergencies to the structured attitude questionnaire prepared by the investigator for study [21].

Practice: It refers to the academic application of knowledge and skills on CPR[21].

\section{AIM OF THE STUDY}

Assess the effect of pregnant advanced cardiopulmonary resuscitation learning package on maternity nurses' knowledge, attitude, and practice.

Research Questions: What are the maternity nurses' knowledge, attitude, and practice regarding advanced cardiopulmonary resuscitation?

Hypotheses: The research hypothesis was that the knowledge, attitude, and practice of the maternity nurses, who attend the educational program, will have an improvement better knowledge, attitude and practice towards advanced cardiopulmonary resuscitation.

\section{METHODS}

Design: Quasi-experimental research design was used in this study.

Setting: The study was conducted at the antenatal outpatient clinic and inpatient obstetric ward, emergency delivery department in Beni-Suef University Hospital and General Beni-Suef Hospital.

Sampling: A convenient sample consist of all nurses were working at maternal emergency department and antenatal outpatient clinic, prenatal inpatient word ( $\mathrm{n}=85$ nurses), from January to May 2016. All questionnaires were distributed by researchers, and interview completed with nurses in 30 minutes during their hospital shifts.

\section{Tool of Data Collection}

Interviewing structured questionnaire was used to collect data. It designed by the researcher based on the related literature, it tested for validity on ten nurses who excluded from the study sample. It entitled two main parts:

Structured interview questionnaire form: This tool was used to collect background data about nurses (Age, years of experience, level of education, shifts, and unit ofwork).

Pre-post-test: The study tool divided into three parts and covered the following items; questionnaire designed by researchers based onthe literature review to assess knowledge first part (14 questions), the second part to evaluate the attitude (6 questions) however the scoring and third part to measure the level of practice (24 steps) Scoring system: The total knowledge score for total knowledge and attitude questions divided as (Low Medium - High-Very high) and for practice satisfactory and unsatisfactory.

\section{Operational Design}

During this phase, the researcher worked on explaining the learning package to nursing staff and distributed booklets containing the Knowledge regarding the advanced CPR for pregnant women and the procedure of advanced CPR in Arabic with pictures so the process could be easily understood by the nurses to apply. Once the nurses were ready to start the program arranging for a proper time to all nurses attained the educational course in one session for theory and one session for practice, researchers collected pre-test before the program started. The learning Package total duration was thirty minutes. 
Impact of Pregnant Advanced Cardiopulmonary Resuscitation Training Program on Maternity Nurses' knowledge, Attitude and Practice in Beni-Suef City

\section{Administrative Design}

Formal letters were issued from the Faculty of Nursing, Beni-Suef University to the medical director of the studysettings. The researcher met with nurses and explained the aim and the process of the study. Nurses' Verbal consents were obtained. Complete confidentiality of any obtained information was ensured. The researcher also assured the administration that the study would not affect the work in the study settings. The results of the study will be provided to the hospitals' authorities to maximize its benefits.

\section{Statistical Design}

Statistical analysis was done using SPSS 22.0 statistical software packages. Data were presented using descriptive statistics in the form of frequencies and percentages, and means and standard deviations for quantitative variables. Quantitative continuous data were compared using student t-tests in case of comparisons between two groups. Paired t-tests were used for pre-post comparisons of the same patients.

\section{RESULTS}

The socio-demographic characteristics of nurses in the study sample are described in Table 1. The age distribution was reported two-thirds were less than 25 years old (84.7\%). Education level was mostly diploma degree approximately half of study sample (50.6\%) and the years of experience ranged from less than 5 years to more than 20 years and about one quarter reported between 15 to 20 years. As for their working shifts around $(70 \%)$ were rotated between all shifts and the table shows that about $30 \%$ working at the obstetric emergency department.

Table1. Socio-Demographic Characteristics of the Study Sample $(n=85)$

\begin{tabular}{|c|c|c|}
\hline Characteristics & No & $\%$ \\
\hline \multicolumn{3}{|l|}{ Age in years: } \\
\hline$<25$ & 72 & 84.7 \\
\hline$\geq 20$ & 13 & 15.3 \\
\hline \multicolumn{3}{|l|}{ Education: } \\
\hline Secondary school & 43 & 50.6 \\
\hline Technical Institute & 25 & 29.4 \\
\hline BNS & 16 & 18.8 \\
\hline Master & 1 & 1.2 \\
\hline \multicolumn{3}{|l|}{ Experiences years } \\
\hline Less 5 years & 31 & 36.5 \\
\hline $5:<10$ & 10 & 11.8 \\
\hline $10:>15$ & 16 & 18.8 \\
\hline $15:<20$ & 20 & 23.5 \\
\hline$\geq 20$ & 8 & 9.4 \\
\hline Shift & 15 & 17.6 \\
\hline Morning & 4 & 4.7 \\
\hline Evening & 6 & 7.1 \\
\hline Night & 60 & 70.6 \\
\hline All Shifts by Rotation & 15 & 17.6 \\
\hline \multicolumn{3}{|l|}{ Workplace } \\
\hline Operation Room & 21 & 24.7 \\
\hline Antenatal & 10 & 11.8 \\
\hline Postnatal & 28 & 32.9 \\
\hline Emergency & 26 & 30.6 \\
\hline
\end{tabular}


Impact of Pregnant Advanced Cardiopulmonary Resuscitation Training Program on Maternity Nurses' knowledge, Attitude and Practice in Beni-Suef City

Figure 1 illustrates the changes scores pre-post learning package of advanced cardiopulmonary resuscitation. Itdemonstrates statistically significant improvement in nurses' knowledge, attitude and practice scores. Moreover, the post-knowledge score reported high score (84.7\%), the attitude modified about (87.1\%) with high level and almost (92.9\%) were met the CPRpractice technique.

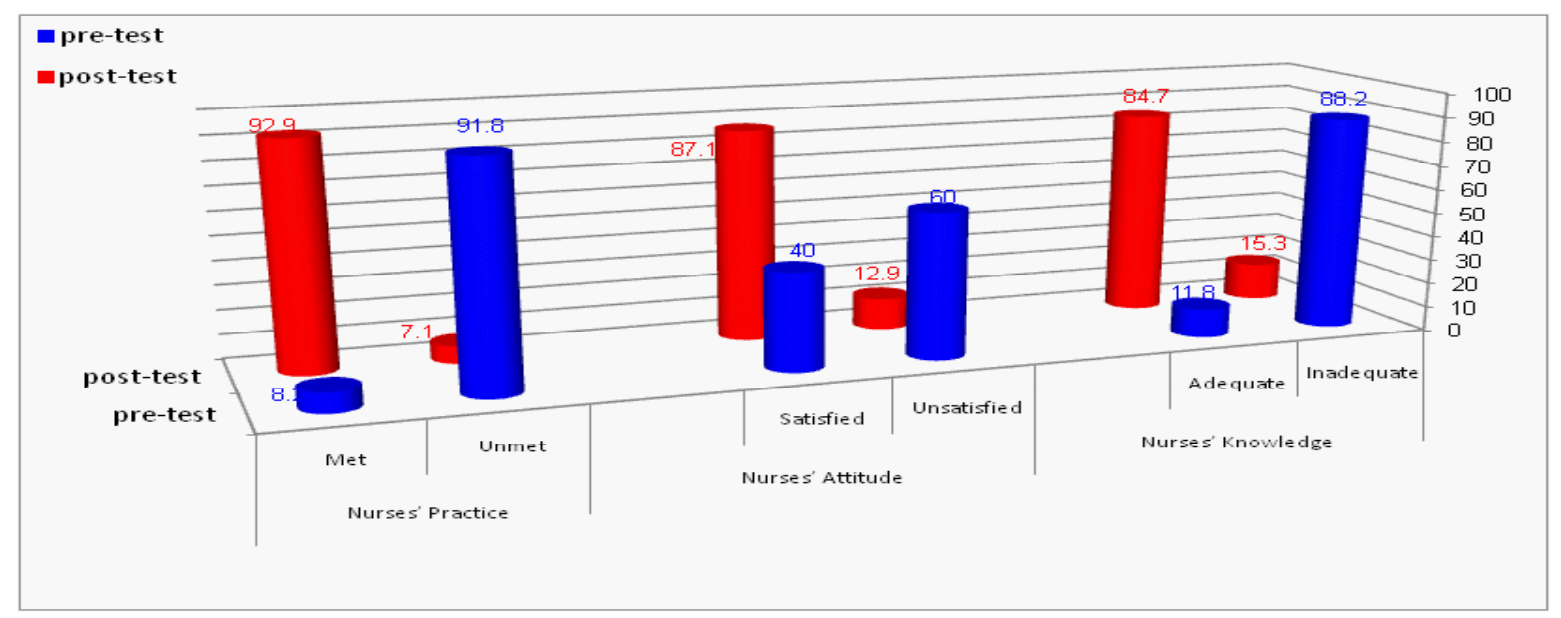

Fig1. pre-post nurses' knowledge, attitude and practice

Table3 describes the pre-post knowledge, attitude, and practice as assessed among nurses in the study sample. It points to statistically significant increases in scores of knowledge, attitude, and practice, $p=0.000$.

Table3. The correlation between Nurses' knowledge, attitude and practice and pre-post learning of CPR.

\begin{tabular}{|l|r|r|r|r|r|}
\hline \multirow{2}{*}{} & \multirow{2}{*}{ pre-post } & \multicolumn{2}{|c|}{$95 \%$ Confidence Interval of the Difference } & \multirow{2}{*}{ t-test } & \multirow{2}{*}{$\boldsymbol{P}$} \\
\cline { 3 - 4 } & & Lower & Upper & -15.048 & $0.000^{* * *}$ \\
\hline Knowledge & $-0.729+0.44$ & -0.82581 & -0.63302 & -7.628 & $0.000^{* * *}$ \\
\hline Attitude & $-0.47+56$ & -0.59327 & -0.34790 & -21.569 & $0.000^{* * *}$ \\
\hline Practice & $-0.84+0.36$ & -0.92515 & -0.76896 & -15 &
\end{tabular}

$\left.{ }^{* * *}\right)$ highly statistical significant difference $(\mathrm{P} \leq 0.001)$

Table4 shows the best fitting multiple regression models for post learning package for Knowledge, attitude, and practice and nurses' experience years. It demonstrates that the statistically significant independent predictors of post-practice score improvement were nurses' experience years was a negative predictor and as indicated by its lowest standardized beta coefficient. As the r-square value indicates, the model explains $96 \%$ of improvement in practice score after application of learning package

Table4. Best fitting linear regression model for post learning package of Knowledge, attitude, and practice and Nurses' Experience years.

\begin{tabular}{|l|r|r|r|c|c|}
\hline \multirow{2}{*}{ Model } & \multicolumn{2}{|c|}{ Unstandardized Coefficients } & \multirow{2}{*}{$\begin{array}{c}\text { Standardized Coef- } \\
\text { ficients }\end{array}$} & $\mathrm{t}$ & \multirow{2}{*}{$\boldsymbol{P}$} \\
\cline { 6 - 6 } & $\mathrm{B}$ & Std. Error & & & \\
\hline (Constant) & 6.572 & 1.488 & -0.001 & 4.415 & $0.000^{* * *}$ \\
\hline Post-Knowledge & -0.006 & 0.424 & -0.182 & -0.014 & 0.989 \\
\hline Post-Attitude & -0.768 & 0.451 & -0.239 & -1.705 & 0.092 \\
\hline Post-Practice & -1.320 & 0.591 & -0.001 & -2.233 & $0.028^{*}$ \\
\hline
\end{tabular}

American Research Journal of Nursing

Page 5 
Impact of Pregnant Advanced Cardiopulmonary Resuscitation Training Program on Maternity Nurses' knowledge, Attitude and Practice in Beni-Suef City

$\left.{ }^{*}\right)$ Mild statistical significant difference $(\mathrm{P} \leq 0.05) \quad\left({ }^{* * *}\right)$ highly statistical significant difference $(\mathrm{P} \leq 0.001)$

Predictors: (Constant), Post-practice, Post-attitude, Post-know

r-square $=0.93$ Model ANOVA: $F=2.76, \mathrm{P}=0.000$

The correlation between pre-post knowledge, attitude, practice and the Nurses' education level and years of experience are displayed in Table 5. It shows astatistically significant positive correlation between the level of education (Diploma, Technical Institute, BSN, Master degrees) and Post-Practice Scores i.e. as the level of education increases the post-practice scores. The nurses' years of experience was negatively and statistically correlated with Post-Practice, i.e. as the years of experience, increase the post-practice scores decrease.

Table5. The correlation between pre-post knowledge, attitude, practice and the nurses' education level and years of experience

\begin{tabular}{|c|c|c|c|c|c|c|c|c|c|}
\hline & & $\begin{array}{c}\text { pre- } \\
\text { knowl- } \\
\text { edge }\end{array}$ & $\begin{array}{c}\text { post- } \\
\text { knowl- } \\
\text { edge }\end{array}$ & $\begin{array}{l}\text { pre-atti- } \\
\text { tude }\end{array}$ & $\begin{array}{c}\text { post- } \\
\text { attitude }\end{array}$ & $\begin{array}{l}\text { pre-prac- } \\
\text { tice }\end{array}$ & $\begin{array}{c}\text { post- } \\
\text { practice }\end{array}$ & $\begin{array}{l}\text { Experi- } \\
\text { ence }\end{array}$ & $\begin{array}{l}\text { Educa- } \\
\text { tion }\end{array}$ \\
\hline \multirow{2}{*}{$\begin{array}{l}\text { pre- } \\
\text { knowl- } \\
\text { edge }\end{array}$} & \begin{tabular}{|l}
$\begin{array}{l}\text { Pearson Cor- } \\
\text { relation }\end{array}$ \\
\end{tabular} & 1 & 0.155 & 0.075 & 0.141 & -0.109 & 0.101 & -0.174 & -0.003 \\
\hline & Sig. & & 0.156 & 0.498 & 0.199 & 0.319 & 0.359 & 0.111 & 0.981 \\
\hline \multirow{2}{*}{$\begin{array}{l}\text { post- } \\
\text { knowl- } \\
\text { edge }\end{array}$} & $\begin{array}{l}\text { Pearson Cor- } \\
\text { relation }\end{array}$ & .155 & 1 & 0.080 & 0.128 & -0.229 & 0.138 & -0.058 & 0.128 \\
\hline & Sig. & .156 & & 0.466 & 0.242 & $0.035^{*}$ & 0.207 & 0.599 & 0.242 \\
\hline \multirow[t]{2}{*}{$\begin{array}{l}\text { pre-atti- } \\
\text { tude }\end{array}$} & \begin{tabular}{|l} 
Pearson Cor- \\
relation
\end{tabular} & .075 & 0.080 & 1 & 0.100 & 0.017 & -0.150 & 0.041 & 0.030 \\
\hline & \begin{tabular}{|l|} 
Sig. \\
\end{tabular} & .498 & 0.466 & & 0.362 & 0.874 & 0.171 & 0.712 & 0.787 \\
\hline \multirow[t]{2}{*}{$\begin{array}{l}\text { post-atti- } \\
\text { tude }\end{array}$} & \begin{tabular}{|l} 
Pearson Cor- \\
relation
\end{tabular} & .141 & 0.128 & 0.100 & 1 & 0.116 & 0.031 & -0.189 & 0.033 \\
\hline & \begin{tabular}{|l|} 
Sig. \\
\end{tabular} & .199 & 0.242 & 0.362 & & 0.293 & 0.781 & 0.083 & 0.763 \\
\hline \multirow[t]{2}{*}{$\begin{array}{l}\text { pre-prac- } \\
\text { tice }\end{array}$} & \begin{tabular}{|l|}
$\begin{array}{l}\text { Pearson Cor- } \\
\text { relation }\end{array}$ \\
\end{tabular} & -.109 & -0.229 & 0.017 & 0.116 & 1 & 0.083 & -0.031 & -0.103 \\
\hline & Sig. & .319 & $0.035^{*}$ & 0.874 & 0.293 & & 0.453 & 0.776 & 0.350 \\
\hline \multirow[t]{2}{*}{$\begin{array}{l}\text { post- } \\
\text { practice }\end{array}$} & \begin{tabular}{|l}
$\begin{array}{l}\text { Pearson Cor- } \\
\text { relation }\end{array}$ \\
\end{tabular} & .101 & 0.138 & -0.150 & 0.031 & 0.083 & 1 & -0.244 & 0.240 \\
\hline & Sig. & .359 & 0.207 & 0.171 & 0.781 & 0.453 & & $0.024^{*}$ & $0.027^{*}$ \\
\hline \multirow[t]{2}{*}{$\begin{array}{l}\text { Experi- } \\
\text { ence }\end{array}$} & $\begin{array}{l}\text { Pearson Cor- } \\
\text { relation }\end{array}$ & -.174 & -0.058 & 0.041 & -0.189 & -0.031 & -0.244 & 1 & -0.560 \\
\hline & Sig & .111 & 0.599 & 0.712 & 0.083 & 0.776 & $0.024 *$ & & $0.000^{* * *}$ \\
\hline \multirow[t]{2}{*}{$\begin{array}{l}\text { Educa- } \\
\text { tion }\end{array}$} & $\begin{array}{l}\text { Pearson Cor- } \\
\text { relation }\end{array}$ & -.003 & 0.128 & 0.030 & 0.033 & -0.103 & 0.240 & -0.560 & 1 \\
\hline & Sig & .981 & 0.242 & 0.787 & 0.763 & 0.350 & $0.027^{*}$ & $0.000 * * *$ & \\
\hline
\end{tabular}

$\left({ }^{*}\right)$ Mild statistical significant difference $(\mathrm{P} \leq 0.05)\left({ }^{* *}\right)$ Moderate statistical significant difference $(\mathrm{P} \leq 0.01)$

$\left.{ }^{* * *}\right)$ A highly statistical significant difference $(\mathrm{P} \leq 0.001)$

\section{Discussion}

Unexpected maternal cardiac arrest and emergencies occur during routine maternity care without professionally trained stafffor such cases may increase maternal mortality care and decrease the quality of care moreover 
Impact of Pregnant Advanced Cardiopulmonary Resuscitation Training Program on Maternity Nurses' knowledge, Attitude and Practice in Beni-Suef City

increase liability risks of anxiety among maternity nurses and other healthcare providers. To improve the training for nurses in the obstetrics departments the researchers of this study developed advanced life support for pregnant women. This skill- enhancing course is designed to improve quality and availability of maternity care for emergency maternal cases.

Cardiopulmonary resuscitation is a lifesaving procedure, performed to preserve patients' life until further management is going to follow. Having basic knowledge of CPR will be a crucial task of medical care providers [21]. This study was done to evaluate knowledge, attitude, and practice of maternity nurses after implementation of an educational program about cardiopulmonary resuscitation. In the present study, a total of 85 nurse's attendees reported a significant improvement in all scores of the knowledge, attitude, and practice. This result a quite close to study done by Belton et al. (2010) who reported improvement of skills and knowledge after maternity emergency carecourse [23]. Aforementioned present study findings are in the agreement with Cohen et al. (2008) who have assessed the knowledge regarding tocardiopulmonary resuscitationof pregnant women and concluded that knowledge of important basic concept including of left uterine displacement and potential of early cesarean delivery during cardiac arrest, moreover reported inadequate knowledge among health care providers [24].

Analyses of the results of the present study have shown differences in the level of education and years of experiences affecting the post-practice after learning package received. This is in the agreement of the recent study done by García et al. (2015) and found a higher level of CPR knowledge (6.7\%) among hospital nursing staff. Nevertheless, this level of knowledge turns out insufficient [25]. The international approval since (2010) sponsored by American Heart Association (AHA) and all organizations are currently in charge of reviewing the clinical guides and protocols established globally. Furthermore, the last update took place in 2010 when important modifications were added in the sequence and the quality of maneuvers to be performed [26, 27]. The cardiopulmonary arrest is proportional to the training of the professionals, studies exist that assess the knowledge of health providers on hospital protocol in case of cardiorespiratory arrest, which concludes on the need for CPR updates due to the low theoretical knowledge of the professionals [28-33].

The extent of our knowledge, unfortunately, no references were found for studies assessing knowledge on basic CPR and advanced CPR in hospital emergency units. In the same line of our study, recent studies recommended to designing a training course for both theory and practice of new technologies on CPR[34]. According to the results of the current study, more than half (50.6\%) of the studysample had a secondary level of nursing education and the most $(88.2 \%, 91.8 \%$ \& $60.0 \%)$ of them had inadequate knowledge, unmet practices and unsatisfied attitude toward CPR before participation in the program. This is in agreement with the findings of Farag (2012) who found 3 types of nursing education relating to three types of nurses in Egypt today. The first level is carried out inhigh schoolsfor nursing education akin to a sort of vocational education that takes place in lieu of high school (referred to as secondary level school in Egypt). The second level is carried out within a technical institute of nursing education (two-years of after high school nursing education).The third or highest level is attained via a University college of nursing(students are trained overfour years plus aone-year internship within a post-secondary school education ortechnical institute of nursing $[35,36]$.

The health sector in Egypt suffers from asevere shortage of qualified nurses (nurses with at the least technical institute, or 2 years of post-high school nursing education). The shortage has implications both forthe quality of healthcare as well as the efficiency of the production of health services. The majority of nurses in Egypt (approximately 90\%) are high school level nurses reflecting an inadequate/insufficient quality of nursing education not only by internationally but even by the region's localstandard. The current approach by the Ministry of Health and Population is to upgrade the standard of quality of nursing education in Egypt to eliminate high school level nursing education in the future; this seems to be the right approach[37]. 
Impact of Pregnant Advanced Cardiopulmonary Resuscitation Training Program on Maternity Nurses' knowledge, Attitude and Practice in Beni-Suef City

If nurse lacks professional knowledge, she should be given appropriate instruction and training. Hence, it is implied that the health care institution must develop comprehensive continuing educational programs[38]. Previous studies reinforced the association between nurses' knowledge and their educational level as well as years of experiences $[35,39]$.Our study finding emphasize on the effect of nurses' education level and years of experience in the knowledge, attitude and practice regarding advanced CPR, this is in contradiction with Citolino, et al (2015) studied the factors affecting the quality of cardiopulmonary resuscitation in inpatient units: perception of nurses and found the professional experience length of time and theshift of nurses didn't influence the perception regarding to CPR application [40]. The more recent research assessed the impact of CPR training program among nurses found astatistically significant increase in mean knowledge level and overall performance before and after the formal certified CPR training program $(\mathrm{P}=0.000)$ [41].

Clinical experience alone doesn't enable healthcare providers to maintain and increase competency in CPR and advanced cardiac life support, however level of education of registered nurses and years of experience are very important as important variables that might affect skill retention and performance of practice [42, 43]. Whereas, the aforementioned study concerning theeffect of application a learning package of advanced CPR on pregnant significantly correlated with the level of nurses' practice is in agreement with Saramma et al. (2016) found the teaching program enhanced nurses' knowledge, skill, attitude and overall confidence as well as helped boost up their morale [41].

\section{CONCLUSION}

Based on the results of our present study, it can be concluded; overall, the majority of nurses' knowledge, attitude, and practices toward cardiopulmonary resuscitation in Beni-Suef city were neither sufficient nor favorable. All of the studied participants didn't practice CPR. After implementation the program, overall, the majority of participants had apositive attitude about CPR. So, training course about advanced cardiopulmonary resuscitation on pregnant women for nurses working in the obstetric department is very important. This study showed that application of such course enhanced and improved nurses' knowledge, attitude and practice. We strongly believe that training program with evaluation increases the knowledge and practice of resuscitation process and motive the nurses to apply latest guidelines laid down by international institutions.

\section{RECOMMENDATION}

Based on the results of the current study, it is recommended that:

1. The developed continuous educational program of maternity advanced CPR for nurses should be implemented on a wider scale and evaluated for furtherimprovement.

2. A simple manual of guidelines of advanced cardiopulmonary resuscitation for pregnant women should be made available in all units to be provided to newly employed nurses.

3. Further research is needed to assess the long-term effects of such program.

\section{REFERENCES}

1. Population Division, Department of Economic and Social Affairs, United Nations, World Population Prospects;(2012).

2. WHO, UNICEF, UNFPA and The World Bank estimates. Trends in maternal mortality; 2013.

3. Campbell O., Gipson R., Issa A. et al. National Maternal mortality ratio in Egypt halved between 1992-93 and 2000. Bulletin of the world Health Organization, 2005; (83) :461- 471. 
Impact of Pregnant Advanced Cardiopulmonary Resuscitation Training Program on Maternity Nurses' knowledge, Attitude and Practice in Beni-Suef City

4. Lee S.,Kim W.,Kang H.,Oh J.,Lim TH.,Lee Y.,Kim C.,Cho JH. Comparisons of the Pentax- AWS, Glidescope,and Macintosh Laryngoscopes for Intubation Performance during Mechanical Chest Compressions in Left Lateral Tilt: Randomized SimulationStudy of MaternalCardiopulmonary Resuscitation. Biomed ResInt,2015;975649.

5. Soar J., Perkins D., Abbas G. et al. European Resuscitation Council Guidelines for Resuscitation 2010 Section 8. Cardiac arrest in special circumstances: electrolyte abnormalities, poisoning, drowning, accidental hypothermia, hyperthermia, asthma, anaphylaxis, cardiac surgery, trauma, pregnancy, electrocution, Resuscitation, 2010; 81(10): 1400-1433,.

6. Gabbott A.Uterine displacement during CPR in the pregnant patient, why bother? Resuscitation, 2013; 84(3): 267-268.

7. LipmanS., Wong Y., Arafeh J., CohenE., and Carvalho B. Transport decreases the quality of cardiopulmonary resuscitation during simulated maternal cardiac arrest. Anesthesia \&Analgesia, 2013; 116(1): 162-167.

8. Lipman S., Daniels K., Cohen S. E., and CarvalhoB. Labor room setting compared with the operating room for simulated perimortem cesarean delivery: a randomized controlled trial. Obstetrics \&Gynecology, 2011; 118(5): 1090-1094.

9. Mogos MF., Salemi JL., Spooner KK., McFarlin BL., Salihu HM. Differences in Mortality Between Pregnant and Nonpregnant Women After Cardiopulmonary Resuscitation. ObstetGynecol, 2016;128(4):880-8.

10. American Heart Association. Cardiac arrest associatedwith pregnancy. Circulation, 2005;112:150-3.

11. Naidoo DP., Desai DK., Moodley J. Maternal deaths due to pre-existing cardiac disease. Cardiovasc J S Afr, 2002;13:17-20.

12. Sogut O., Kamaz A., Erdogan MO., Sezen Y. Successful cardiopulmonary resuscitation in pregnancy: A case report. J Clin Med Res, 2010;2:50-2.

13. American Heart Association. Postresuscitation support. Circulation, 2005;112:84-8.

14. Lavecchia M.,Abenhaim A. Cardiopulmonary resuscitation of pregnant women in the emergency department. Resuscitation, 2015; 91:104-7.

15. Bakhsha F. Assessing the Need and Effect of Updating the Knowledge about Cardio-Pulmonary Resuscitation in Experts. Journal of Clinical and Diagnostic Research, 2010; 4: 2512-2514.

16. Hassan H. Call for psychosocial well-being among pregnant women associated with medical disorder in Beni-Suef governorate. IOSR Journal of Nursing and Health Science. 2016; 5(2): 81-94. doi: 10.9790/19590502048194

17. England M. Review of Psychotherapy for the advanced practice psy- chiatric nurse. Perspectives in Psychiatric Care. 2008; 44(3): 219-220. http://dx.doi.org/10.1111/j.1744-6163.2008.00179.x

18. Sheha E., Hassan H., Gamel W. Association between pre-pregnant overweight and obesity and periodontal disease during pregnancy: a cross sectional study. International Journal of Studies in Nursing, 2018; 3(1): 1-21. doi:10.20849/ijsn.v3i1.207.

19. Sharan R.,Madan A.,Makkar V.,Attri JP. Case report on effective cardiopulmonary resuscitation in a pregnant woman. Anesth Essays Res, 2016; 10(1):122-4. doi: 10.4103/0259-1162.164679.

20. Agrawal S., Singh V., Nayak PK., Thakur P., Agrawal M., Jain A. Polytrauma during pregnancy. J OrthopTraumatolRehabil, 2013;6:63-9. 
Impact of Pregnant Advanced Cardiopulmonary Resuscitation Training Program on Maternity Nurses' knowledge, Attitude and Practice in Beni-Suef City

21. Tsegaye W., Tesfaye M. and Alemu M. Knowledge, Attitude and Practice of Cardiopulmonary Resuscitation and Associated Factors in Ethiopian University Medical Students. Journal of General Practice, 2015; 4(3): 1-5. doi.org/10.4172/2329-9126.1000206.

22. American Heritage ${ }^{\circ}$ Dictionary of the English Language, Fifth Edition. (2011). Retrieved June 272017 from http://www.thefreedictionary.com/perception

23. BeltonS., Campbell M., FoxleyS.,Hamerton B., GladmanJ., McGrath S., PillerN., Saunders N., Vaughan F. Evaluating thelong-term effectivenessof the Maternity Emergency Care course in remote Australia. Women Birth,2010; 23(2):60-6.

24. Cohen SE., Andes LC.,Carvalho B. Assessment of knowledge regarding cardiopulmonary resuscitation of pregnant women. Int J ObstetAnesth,2008; 17(1):20-5

25. García S., Alemán A., Luis J., Pérez A., Hernández N., Valverde I., Castro R. Assessment of the knowledge level and its relevance in terms of CPR in medical personnel of the hospital emergency medical system of the Autonomous Community of the Region of Murcia. Enfermería Global, 2015; (39):246-260.

26. HazinskiMF., Nolan JP., Billi JE., Böttiger BW., Bossaert L., Caen ARd. , et al. Executive Summary 2010 International Consensus on Cardiopulmonary Resuscitation and Emergency Cardiovascular Care Science With Treatment Recommendations, 2010;122:S250-S75.

27. Sayre MR., Berg MD., Berg RA., Bhanji F., Billi JE., Callaway CW., et al. Aspectosdestacados de lasguías de la American Heart Association de 2010 para RCP y ACE. American Herat Association. 2010. Acceso 6 julio 2014. Disponible en: http://cmedica.coe.es/WEB/EVENTOSHOME.nsf/b8c1dabf8b650783c1256d560051ba.

28. Rosón JF., Bailén MR., Rodríguez JP., Cuadra JAR., Cruz AC., Castellanos MAD. Evaluación del contenido y funcionamiento de los carros de reanimacióncardiopulmonar de unhospital. MedicinaIntensiva, 2003;27(6):399-403.

29. Nyman J., Sihvonen M. Cardiopulmonary resuscitation skills in nurses and nursing students. Resuscitation, 2000;47(2):179-84.

30. Rodríguez-Borrajo S., de Lahidalga-Martínez OM., de Cortazar AG., ArriaranMendialdua I., Latorre-García K. Conocimientos de lasenfermeras de hospitalización del plan de atención a lassituaciones de amenaza vital inmediata. EnfermeríaClínica, 2008;18(4):190-6.

31. Almeida AOd., Araújo IEM, Dalri MCB, Araujo S. Theoretical knowledge of nurses working in non-hospital urgent and emergency care units concerning cardiopulmonary arrest and resuscitation. Revista LatinoAmericana de Enfermagem, 2011;19:261-8.

32. Camargo JCM., Velázquez MR-B., Martínez MM., Ramírez AA., López JFR., Serrano PR., et al. Conocimientossobreresucitacióncardiopulmonar del profesionalenfermero en unidades sin monitorización de pacientes. Metas de enfermería, 2011;14(1):10-5.

33. Passali C., Pantazopoulos I.,Dontas I., Patsaki A., Barouxis D., Troupis G., et al. Evaluation of nurses' and doctors' knowledge of basic \& advanced life support resuscitation guidelines. Nurse Education in Practice, 2011;11(6):365-9.

34. Lo BM., Devine AS., Evans DP., Byars DV., Lamm OY., Lee RJ., et al. Comparison of traditional versus highfidelity simulation in the retention of ACLS knowledge, 2011;82(11):1440-3.

35. Hassan H., Mohamady Sh., \& Abd El-Gawad N. Protocol for improving nursing performance towards placental examination at labor units. Clinical Nursing Studies, 2017; 5(2): 1-11. http://dx.doi. org/10.5430/cns.v5n2p1.

American Research Journal of Nursing

Page 10 
Impact of Pregnant Advanced Cardiopulmonary Resuscitation Training Program on Maternity Nurses' knowledge, Attitude and Practice in Beni-Suef City

36. Farag M. School of Public Health University of Saskatchewan, 2012.

37. Nasr E, Hassan H. Association between quality of family planning services and client's satisfaction level in maternal and child health centers in Port Said city. Journal of Nursing Education and Practice. 2016; 6(1): 85-99. doi: 10.5430/jnep.v6n1p85

38. Farag M. Belfer Center for Science and International Affairs, Harvard University, 2008.

39. Hassan H, Nasr E. Improving nurses' knowledge and skills regarding tocolytics for inhibiting preterm labor. Clinical Nursing Studies. 2017; 5(1): 1-12. https://doi.org/10.5430/cns.v5n1p1.

40. CitolinoCM.,Santos ES., Silva RdeC.,NogueiraLde S. Factors affecting the quality of cardiopulmonary resuscitation in inpatient units: perception of nurses. Rev Esc EnfermUSP,2015;49(6):908-14.

41. Saramma PP., Raj LS., Dash PK., SarmaPS. Assessment oflong-term impact of formal certified cardiopulmonary resuscitation training program among nurses. Indian J CritCare Med,2016;20(4):226-32.

42. Jensen ML., Lippert F, Hesselfeldt R., Rasmussen MB., Mogensen SS., Jensen MK., et al. The significance of clinical experience on learning outcome from resuscitation training-a randomised controlled study, 2009;80:238-43

43. Smith KK., Gilcreast D., Pierce K. Evaluation of staff's retention of ACLS and BLS skills, 2008;78:59-65.

Citation: Safaa Soliman Ahmed, Nahed Mousa Saber, Hanan Elzeblawy Hassan, Eman Hessien Heggy "Impact of Pregnant Advanced Cardiopulmonary Resuscitation Training Program on Maternity Nurses' knowledge, Attitude and Practice in Beni-Suef City". American Research Journal of Nursing. 2017; 3(1): 1-11.

Copyright (c) 2017 Safaa Soliman Ahmed, Nahed Mousa Saber, Hanan Elzeblawy Hassan, Eman Hessien Heggy, This is an open access article distributed under the Creative Commons Attribution License, which permits unrestricted use, distribution, and reproduction in any medium, provided the original work is properly cited. 